\title{
COINTEGRATION AND CAUSALITY ANALYSIS ON DEVELOPED ASIAN MARKETS FOR RISK MANAGEMENT AND PORTFOLIO SELECTION
}

\author{
Aldrin Herwany \\ Erie Febrian
}

Both practitioners and academics demand a linkage model across financial markets, particularly among regional capital markets, for both risk management and portfolio selection purposes. Researchers frequently use cointegration and causality analysis in investigating the dependence or co-movement of three or more stock markets in different countries. However, they mostly conduct causality in mean tests but not causality in variance tests.

This study assesses the cointegration and causal relations among seven developed Asian markets, i.e., Tokyo, Hong Kong, Korea, Taiwan, Shanghai, Singapore, and Kuala Lumpur stock exchanges, using more frequent time series data. It employs the recently developed techniques for investigating unit roots, cointegration, time-varying volatility, and causality in variance. For estimating portfolio market risk, this study employs Value-atRisk with delta normal approach. The results would recommend whether fund managers are able to diversify their portfolio in these developed stock markets either in long run or in short run.

Keywords: Asian Stock Markets; causality; cointegration; portfolio selection; risk management 
Gadjah Mada International Journal of Business, September - December 2008, Vol. 10, No. 3

\section{Introduction}

In borderless investment activities, investors, portfolio managers, and policymakers seek for a model that can disclose linkages and causality across financial markets, especially markets in a neighboring area. The model will provide them with a better view of market movement and, therefore, enable them to appropriately price underlying assets and their derivatives, as well as to hedge the associated portfolio risks. Cointegration analysis has been the most popular approach employed by academics and stock market researchers to developing such a linkage and causality model.

Cointegration analysis was initially introduced through influential contributions by Granger(1981), Engle and Granger (1987), and Granger and Hallman (1991). Such an analysis can reveal regular stochastic tendencies in financial time series data and be useful for long-term investment analysis. The analysis considers the $I(1)-I(0)$ type of cointegration in which linear permutations of two or more I (1) variables are $I(0)$ (Christensen and Nielsen, 2003). In the bivariate case, if $y_{t}$ and $x_{t}$ are $I$ (1) and hence in particular nonstationary (unit root) processes, but there exists a process $e_{t}$ that is $I(0)$ and a fixed $\beta$ such that: $y_{t}=\beta^{\prime} x_{t}+e_{t}$ then $x_{t}$ and $y_{t}$ are defined as cointegrated. Thus, the non-stationary series shift together in the sense that a linear permutation of them is stationary and therefore a regular stochastic trend is shared.
Granger and Hallman (1991) prove that investment decisions merely based on short-term asset returns are inadequate, as the long-term relationship of asset prices is not considered. They also show that hedging strategies developed based on correlation require frequent rebalancing of portfolios, whereas those developed strictly based on cointegration do not require rebalancing. Lucas (1997) and Alexander (1999), using applications of cointegration analysis to portfolio asset allocation and trading strategies, have proven that index tracking and portfolio optimization based on cointegration rather than correlation alone may result in higher asset returns. Meanwhile, Duan and Pliska (1998), developing a theory of option valuation with cointegrated asset prices, reveal that cointegration method can have a considerable impact on spread option price volatilities. Furthermore, economic policymakers must have comprehensive knowledge of price movement transmission in regional equity markets, especially during the period of high volatility. Appropriate policy may be designed to lessen the degree of financial crisis. Therefore, research on cointegration and causality among regional equity markets is essential. Cointegration approach complements correlation analysis, as correlation analysis is appropriate for short-term investment decisions while cointegration-based strategies are necessary for long-term investment. 
Herwany \& Febrian-Cointegration and Causality Analysis on Developed Asian

\section{Objectives and Structure of the Study}

This paper is aimed at identifying the long-run equilibrium relationships among seven developed Asian markets, i.e., Tokyo, Hong Kong, Korea, Taiwan, Shanghai, Singapore, and Kuala Lumpur stock exchanges, using more frequent time series data. The paper also purports to explain risk performance of the observed markets.

Earlier part (Section 3) of this paper is focused on one or more of the observed markets and the associated linkages among the markets through sample data and key descriptive statistics. It is then followed by a brief description of Vector Error Correction Model of Price Indices and Returns (Section 4). The procedure employed in this paper was the one originally proposed by Hall and Milne (1994) and applied by Liu and Romilly (1997), Chandana and Paratab (2002), Liu et al. (2002) who realize a causality analysis for integrated series of order one, $I(1)$, with cointegration by generating a VEC. This mechanism enables us to study the relationships in multivariate causality framework in Section 5. Finally, the results are concluded in Section 6.

\section{Sample Data and Descriptive Statistics}

Sample data used in this study are taken from seven indices of prominent Asian economies, i.e., Japan, China (Hong Kong and Shanghai), Korea,
Taiwan, Singapore, and Malaysia. The observations are conducted in three periods: longer period (1/3/2000 - 12/ $31 / 2007)$, first shorter period (1/3/2000 - 12/31/2003), and second shorter pe$\operatorname{riod}(1 / 2 / 2004$ - 12/31/2007). This division of observation periods is aimed at revealing the impact of particular economic condition on the indices, as well as assessing the cointegration in different durations.

All the indices have been adjusted to stock-splits, mergers and acquisition. We avoid transforming the three indices into a common currency. Instead, we use the nominal indices in domestic currencies to evade problems associated with transformation due to fluctuations in cross-country exchange rates and also to avoid the restrictive assumption that the relative purchasing power parity holds. In addition, we also implicitly assume that dividends are not vital to our analysis, as in general dividends do not reveal the level of volatility that would be necessary to influence the null hypothesis of 'no cointegration' among a set of stock price indices (see Dwayer and Wallace 1992).

As can be seen from Figure 1, Hong Kong and Tokyo indices record market capitalizations that are much higher than those of the other observed indices. In the end of 2007, Tokyo and Taiwan indices showed negative growth, i.e., -19 percent and -3 percent, respectively, while the other indices recorded large positive growth. The indices of Shanghai, Korea, Kuala Lumpur, Hong Kong, and Singapore 
Gadjah Mada International Journal of Business, September - December 2008, Vol. 10, No. 3

Figure 1. Movements of Major Asian Indices in the Observed Period (N225, HSI, KS11, TWII, SSEC, STI, and KLSE)

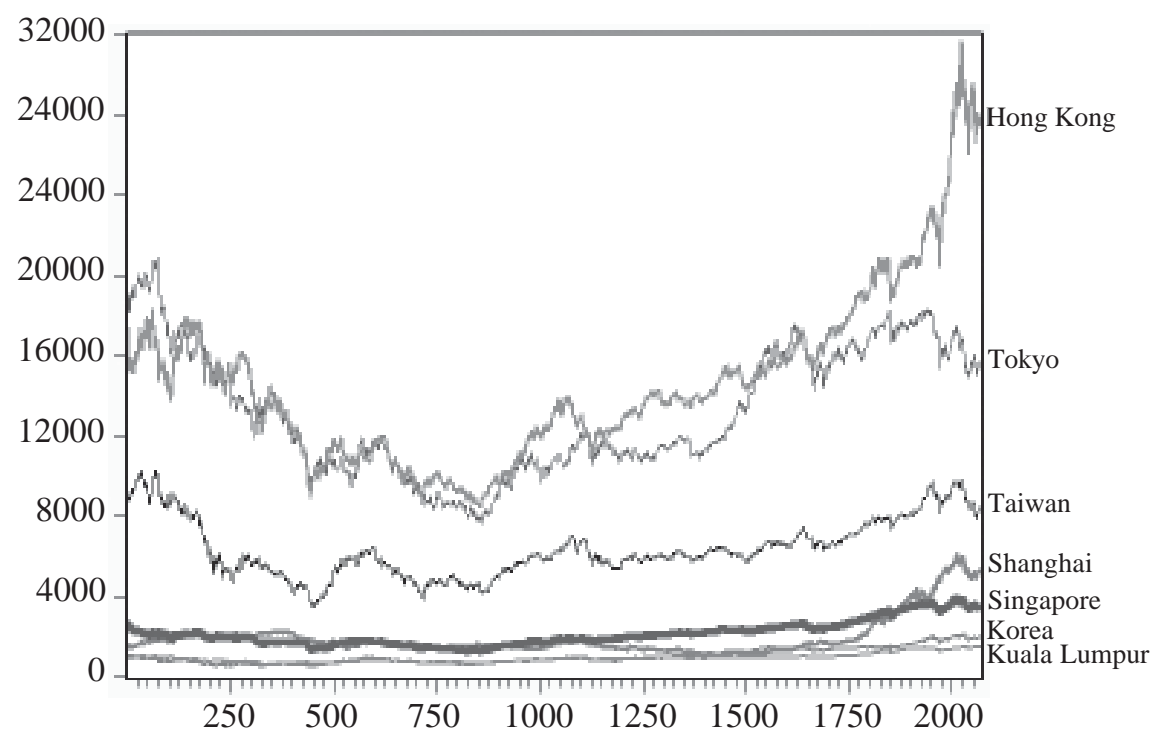

Source: www.finance.yahoo.com

logged increases by 274 percent, 79 percent, 73 percent, 60 percent, and 35 percent, consecutively.

Table 1 shows that the return mean values in the longer period vary in negative-positive magnitudes. Tokyo and Taiwan indices show negative return means, i.e. -0.01 percent and 0.0024 percent, respectively. The rest observed indices record positive returns, and Shanghai shows the highest return $(0.07 \%)$ during the observation period of 2000.1-2007.12. Meanwhile, in the same observation period, Korean index exhibits the highest risk level (the largest return standard deviation) of 1.78 percent, and Kuala Lumpur index shows the lowest one of less than one percent. Table 1 also shows that the indices' skewness val- ues are negative, except for that of Shanghai index, and that all indices have kurtosis values larger than three, which indicate fat-tails. Therefore, the Jarque-Bera (JB) values of the indices imply that none of the indices is normally distributed. The test statistic is computed as:

$$
\frac{\mathrm{n}}{6}\left[\mathrm{~S}^{2}+\frac{(\mathrm{K}-3)^{2}}{4}\right]
$$

where

$\mathrm{S}=$ skewness, and

$\mathrm{K}=$ kurtosis.

In the first shorter period 2000.1 2003.12, Shanghai index exhibits the only positive average return, i.e., 0.01 percent, as can be seen in Table 2 . 
Herwany \& Febrian-Cointegration and Causality Analysis on Developed Asian

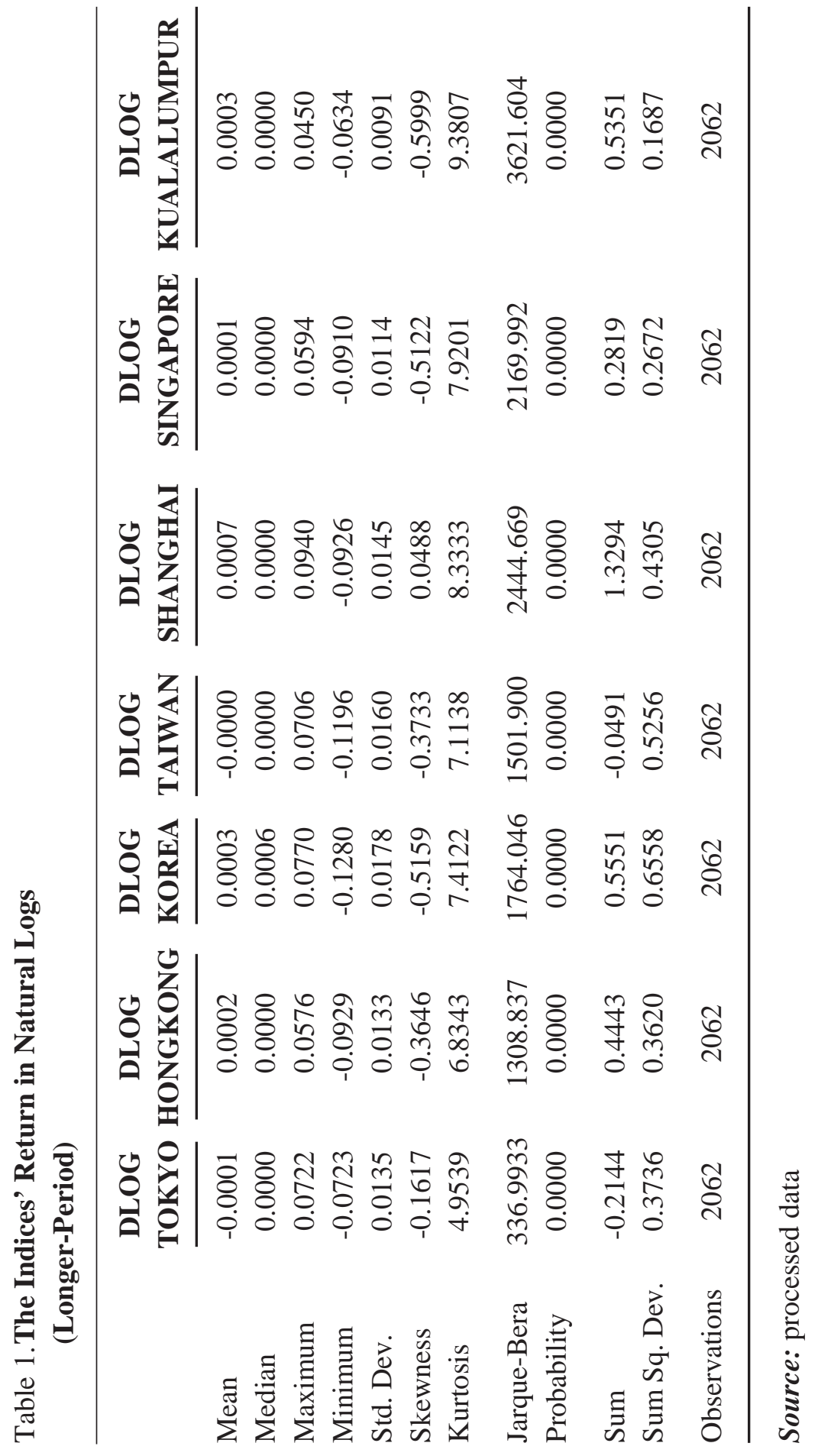


Gadjah Mada International Journal of Business, September - December 2008, Vol. 10, No. 3

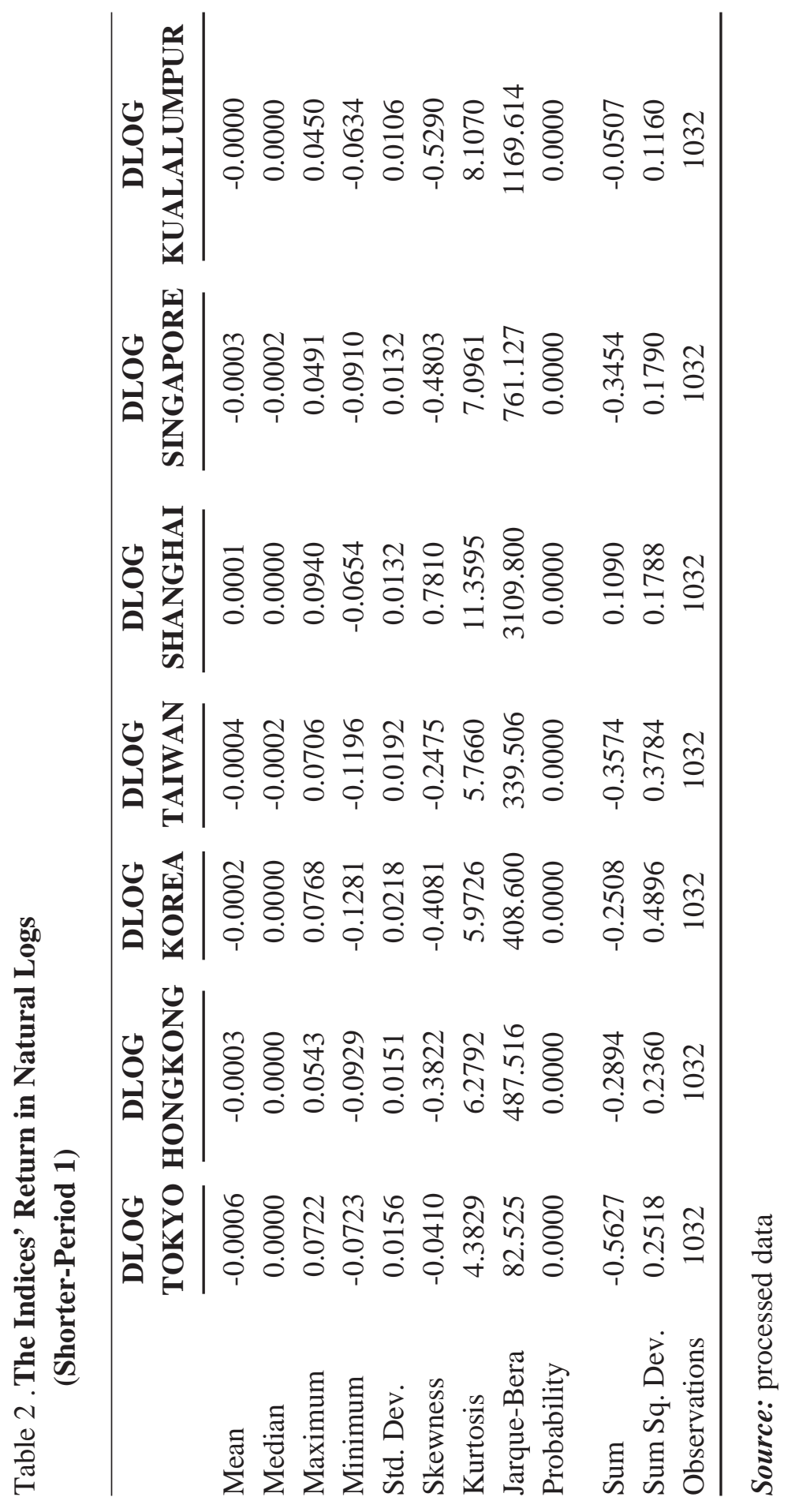


Herwany \& Febrian-Cointegration and Causality Analysis on Developed Asian

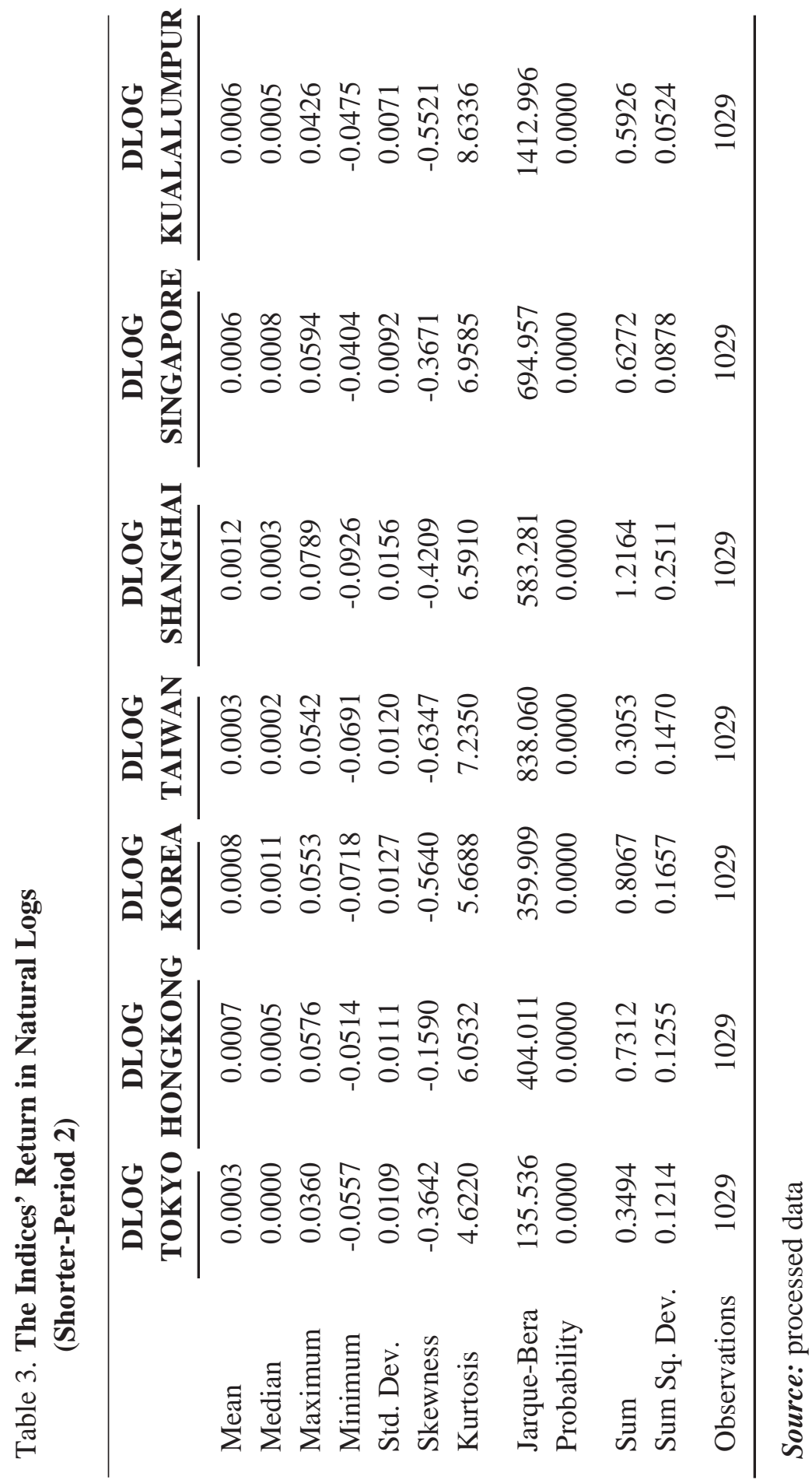


Tokyo index presents the lowest average return, i.e., -0.06 percent. In this period, the highest and the lowest risk levels, indicated by the standard deviation values, are shown by Korea and Kuala Lumpur indices, respectively. All indices show kurtosis values larger than three, indicating fattails and leading to non-normal distribution. In the second shorter period, 2004.1 - 2007.12, Shanghai index shows the highest return average of 0.12 percent while both Tokyo and Taiwan indices show the lowest return average of 0.03 percent. Table 3 reveals that the combination of respective skewness and kurtosis values leads to non-normal distribution, as none of the skewness is zero and none of the kurtosis is three.

Overall, Shanghai index consistently shows positive and the highest returns whereas Tokyo index always exhibits the lowest returns in all observed periods. In the risk side, Kuala Lumpur index consistently shows the most stable price movement in all periods. The risk of Korean index is the highest in the longer period and in the first shorter period. In the second shorter period, Shanghai index records the highest risk level, which confirms the assumption of "high-risk for highreturn."

Table 4 reveals the correlation between two observed indices. Corre- lation between Singapore and Hong Kong indices is the highest, while that between Tokyo and Shanghai indices is the lowest. All indices connected with Shanghai index show very low correlation coefficients, implying that investors would achieve the expected diversification if they include Shanghai index in their indices portfolios.

Subsequently, it can be seen in Table 5 that Singapore-Hong Kong index pair demonstrates the highest correlation coefficient (0.59). Meanwhile, Shanghai, Taiwan, and Kuala Lumpur indices show weak correlations with other indices in the region.

Correlation coefficients in the second shorter period are consistent with those in the first shorter period. Singapore-Hong Kong index pair again exhibits the highest correlation coefficient (0.684), while Shanghai is constantly weakly correlated with other observed indices.

In general, if an investor is to develop a portfolio of Asian indices, Shanghai index can be the first choice, as it consistently proves ineffectual correlations with other observed Asian indices. On the contrary, Hong Kong index may increase the risk to such an Asian-indices portfolio as it consistently shows high correlations with other indices. 
Herwany \& Febrian-Cointegration and Causality Analysis on Developed Asian

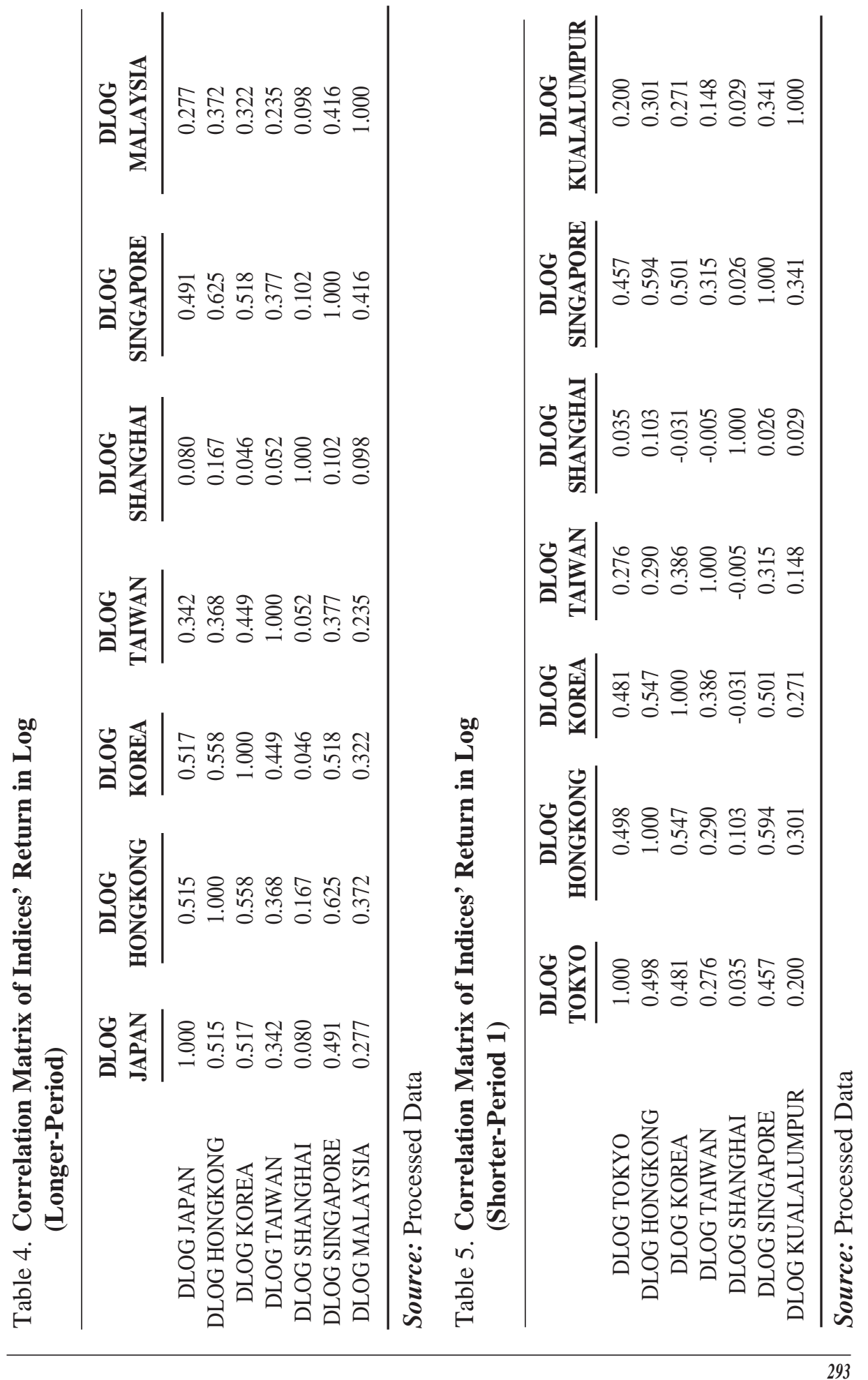


Gadjah Mada International Journal of Business, September - December 2008, Vol. 10, No. 3

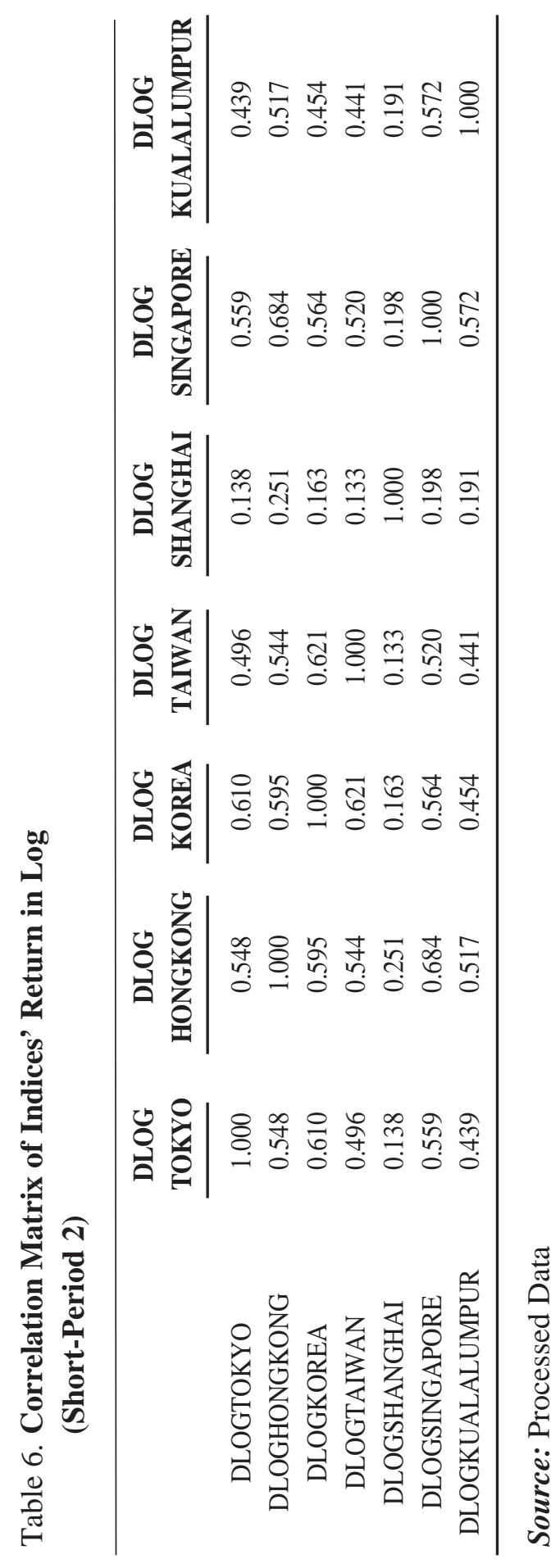


Herwany \& Febrian-Cointegration and Causality Analysis on Developed Asian

\section{VEC Model of Price Indices and Returns}

This study assesses the long-term equilibrium relationships as well as the short-term dynamics among seven equity markets using the Johansen and Juselius' (1990) model. If the indices share a common stochastic trend, they can be considered cointegrated (Christensen and Nielsen 2003). The presence of cointegration forms the basis of the Vector Error Correction (VEC) specification. Below is vector auto-regressive (VAR) model of order $p:$

$$
X_{t}=\mu \sum_{i=1}^{p} A_{t-1}+\varepsilon_{t}
$$

where $X_{t}$ is a column vector of variables, which are the log price indices; $\mu$ is a vector of constants; $\varepsilon_{t}$ is a vector of innovations, random errors usually assumed to be contemporaneously correlated but not autocorrelated; and $p$ is the number of lags of variables in the system.

If the variables in the vector $\mathrm{X}$ are integrated of order, say one, 1(1), and are also cointegrated, then the cointegration restriction has to be included in the VAR in equation (2). The Granger Representation Theorem (Engle and Granger, 1987) states that variables, individually determined by permanent shocks, are cointegrated if and only if there is a vector error correction representation of the time series data. With this restriction imposed, a VAR model is referred to as VEC. Variables in the model enter the equation in their first derivatives, and the error correction terms are added to the model. Consequently, the VEC has cointegration relations built into the specification so as to confine the longterm behavior of the endogenous variables to converge to their cointegrating relationships while allowing for shortterm dynamics. Biases from long-term equilibrium are corrected through a series of partial short-term adjustments.

The VEC representation of Equation (3), following Johansen and Juselius (JJ) is:

$$
\mathrm{X}_{\mathrm{t}}=\mu \sum_{\mathrm{i}=1}^{\mathrm{p}} \Gamma \Delta \mathrm{X}_{\mathrm{t}-1}+\alpha \beta^{\prime} \mathrm{X}_{\mathrm{t}-1}+\varepsilon_{\mathrm{t}} \ldots
$$

where,

$\Gamma$ are $(\mathrm{m} \mathrm{x} \mathrm{m})$ coefficient matrices $(\mathrm{i}=$ $1,2, \ldots . ., \mathrm{k})$,

$\alpha, \beta$ are (m x r) matrices so that $0<\mathrm{r}<$ $\mathrm{m}$,

where $r$ is the number of linear combinations of the elements in $X_{t}$ that are affected only by transitory shocks.

Matrix $\beta$ is the cointegrating matrix of $\mathrm{r}$ cointegrating vectors, $\beta_{1} \beta_{2}, \ldots$, $\beta_{\mathrm{i}}$. The $\beta$ vectors represent estimates of the long-run cointegrating relationships among variables in the system. The error correction terms, $B^{\prime} X_{t-1}$, are the mean reverting weighted sums of cointegrating vectors. The matrix a is the matrix of error correction coefficients that measures the speed at which the variables adjust to their equilibrium values. It is obvious that the model 
Gadjah Mada International Journal of Business, September - December 2008, Vol. 10, No. 3

in Equation (3) is the standard VAR in the first differences of $X_{t}$, augmented by the error correction terms, $\alpha B^{\prime} X_{t}$. The $J J$ method provides maximumlikelihood estimates of a and B'.

\section{Empirical Estimation and Results}

The very early phase in the estimation process is to decide the order of integration of the individual price index series in natural log levels. The logs of the indices, denoted as N225, HSI, KS11, TWII, SSEC, STI, and $K L S E,{ }^{1}$ are tested for unit roots using the augmented Dickey-Fuller (ADF) (1979) test using the lag structure indicated by Schwarz Bayesian Information Criterion (SBIC). The $p$-values used in the tests are the MacKinnon (1996) one-sided $p$-values. The test results, as can be seen in Table 7 , indicate that the null hypothesis that the price index in log levels contains a unit root cannot be rejected for each of the seven price series. Then, unit root tests are performed on each of the price index series in log first differences. The null hypothesis of a unit root could be rejected for each of the time series. No further tests are performed since each of the series is found to be stationary in log first differences. The finding that each price series is non-stationary implies that each of the observed markets is weakly efficient.
The second phase involves an assessment on the seven market series for cointegration. The cointegration test is to determine whether or not the seven non-stationary price indices share a common stochastic trend. The estimated cointegrating equation is as follows:

$$
\begin{aligned}
{\mathrm{IN} 255_{\mathrm{t}}=} & \alpha_{0}+\alpha_{1} 1 \mathrm{HSI}_{\mathrm{t}}+\alpha_{2} 1 \mathrm{KS}_{1}+ \\
& \alpha_{4} 1 \mathrm{TWII}_{\mathrm{t}}+\alpha_{5} 1 \mathrm{STI} \mathrm{t}_{\mathrm{t}}+ \\
& \alpha_{6} \mathrm{LKLSE}_{\mathrm{t}}+\varepsilon_{\mathrm{t}} \ldots \ldots \ldots \ldots \ldots(4)
\end{aligned}
$$

where $L N 225_{t}$ is logarithm value of Nikkei 225 at $\mathrm{t}=1,2,3, \ldots, \alpha_{0}$ is a constant, while $\alpha_{1}, \ldots, \alpha_{6}$ are regression coefficients on the respective independent variables. The independent variables of $L H S I$, LKS11, LTWII, $L S S E C_{t}, L S T I$, and $L K S E_{t}$ are in logarithm values, which reflect the respective observed indices at $\mathrm{t}=1,2,3, \ldots$ Finally, $\varepsilon_{\mathrm{t}}$ is error term.

All the indices are found cointegrated in the three different observation periods at the significance level of five percent. This indicates that an investor may not form an efficient portfolio if he or she includes the observed indices in his or her portfolio, as the intended diversification may not be achieved.

$J J$ estimation procedure that uses the maximum likelihood method is then employed. The cointegration test assumes no deterministic trend in the

\footnotetext{
${ }^{1}$ N255, HIS, KS11, TWII, SSEC, STI, and KLSE stand for Nikkei 225, Hang Seng Index, KOSPI Composite, SSE Composite Index- Shanghai, Index Korea, TSEC weighted index, Straits Times Index, Kuala Lumpur Stock Exchange, respectively
} 
Herwany \& Febrian-Cointegration and Causality Analysis on Developed Asian

Table 7. Augmented Dickey Fuller (ADF) Unit Root Test of Indices

\begin{tabular}{|c|c|c|c|c|}
\hline $\begin{array}{l}\text { Daily Closing } \\
\text { Price Indices }\end{array}$ & Period & Lag & Test Statistic & SIC Values \\
\hline N255 & Long & 1 & -45.546 & -5.772 \\
\hline HSI & Long & 1 & -25.744 & -5.821 \\
\hline KS11 & Long & 1 & -45.161 & -5.208 \\
\hline TWII & Long & 1 & -23.727 & -5.433 \\
\hline SSEC & Long & 1 & -44.851 & -5.625 \\
\hline STI & Long & 1 & -44.654 & -6.107 \\
\hline KLSE & Long & 1 & -38.782 & -6.590 \\
\hline N255 & Short 1 & 1 & -32.237 & -5.466 \\
\hline HSI & Short 1 & 1 & -30.836 & -5.534 \\
\hline KS11 & Short 1 & 1 & -32.086 & -4.801 \\
\hline TWII & Short 1 & 1 & -16.924 & -5.057 \\
\hline SSEC & Short 1 & 1 & -30.942 & -5.809 \\
\hline STI & Short 1 & 1 & -30.659 & -5.812 \\
\hline KLSE & Short 1 & 1 & -27.364 & -6.266 \\
\hline N255 & Short 2 & 1 & -32.120 & -6.195 \\
\hline HSI & Short 2 & 1 & -17.270 & -6.160 \\
\hline KS11 & Short 2 & 1 & -31.461 & -5.881 \\
\hline TWII & Short 2 & 1 & -31.414 & -6.005 \\
\hline SSEC & Short 2 & 1 & -32.240 & -5.461 \\
\hline STI & Short 2 & 1 & -33.491 & -6.516 \\
\hline KLSE & Short 2 & 1 & -15.997 & -7.070 \\
\hline
\end{tabular}

Source: Processed Data

$* * *$ at $1 \%$ level of Significance

** at 5\% level of Significance

* at $5 \%$ level of Significance

series and uses lag intervals from 1 to 1 as suggested by the SBIC for appropriate lag length. However, it would not make any difference even if we chose AIC (Akaike Information Criterion) because both the AIC and SBIC suggest the same lag length as well as the assumptions for the test. The assumptions of the test are that the indices in log levels have no deterministic trend and the cointegrating equation has an intercept but no intercept in the VAR. 
The trace test, which examines the null hypothesis of $r$ cointegrating relations against $k$ cointegrating relations, where $k$ is the number of endogenous variables, for $r=0,1, \ldots, k$. The existence of $k$ cointegrating relations implies that there is no cointegration between each pair of the seven series. The maximum Eigen's value test, which tests the null of $r$ cointegrating relations against the alternative of $r+$ 1 cointegrating relations, indicates the prevalence of one cointegrating equation at five percent significance level. The critical values used by Osterwaldlenum (1992) are slightly different from those reported in $J J$. The cointegrating relationship is normalized in N255. The cointegrating vector of the seven daily price indices, normalized in IN255 is: [1 3.1 -0.4 $3.23-0.33-5.27$ 5.09]. The cointegrating equation indicates that $N 255$ and HSI indices adjust one-to-one in the long run, and results in a value greater than one for the rest of indices, except for KS11.

We test for market indices' cointegration between the pairs, and find that all the pairs are cointegrated. The test results are not presented as our focus is the relationships among the seven markets. The finding that the market indices are cointegrated means that there is one linear combination of the seven price series that forces these indices to have a long-term equilibrium relationship even though the indices may wander away from each other in the short run. It also implies that the returns on the indices are correlated in the long run. The message for long-term international investors is that it does not matter, in terms of portfolio returns, whether investors in the observed Asian countries hold a fully diversified portfolio of stocks contained in all of the seven indices or hold portfolios consisting of all stocks of one index only.

Cointegration between the portfolio and the index is assured when there is at least one portfolio of stocks that has stationary tracking error, that is, the difference between the portfolio of stocks and the stock index is stationary, or to put it differently, the price spread between the two is mean-reverting. However, in the short run, the two may deviate from each other with the potential for higher returns on the portfolio relative to the index. Therefore, investors may still be able to earn excess returns in the short run by holding a portfolio of stocks from the seven markets.

The final phase is the estimation of the three-variable VEC model. In terms of this study analysis, the estimated vector error-correction model of price indices has the following form:

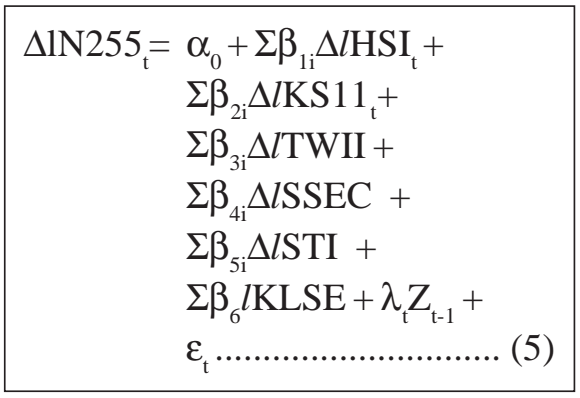


where $\Delta l$ are the first log differences of the seven market indices lagged $p$ periods; $Z_{t-1}$ are the equilibrium errors or the residuals of the cointegrating equations, lagged one period; and $\lambda_{i}$ are the coefficients on the error-correction terms. The lag lengths for the series in the system are determined according to the SIC. The suggested lag length is from one to one. No restriction is imposed in identifying the cointegrating vectors. The coefficients on the error correction terms are denoted by $\lambda$.

The estimated results can be seen in Tables 8, 9, and 10. For brevity, the estimated coefficients on the lagged variables along with the $t$-statistics are presented without the asymptotic standard errors corrected for degrees of freedom. On the bottom of the tables, the log likelihood values, the AIC and SBIC are reported.

Three types of inferences concerning the dynamics of the seven markets can be drawn from the reported results of the VEC model in Tables 8,9 , and 10 . The first one is concerned about whether the left hand side variable in each equation in the system is endogenous or weakly exogenous. The second type of inference is about the speed, degree, and direction of adjustment of the variables in the system to restore equilibrium following a shock to the system. The third type of inference is associated with the direction of short-run causal linkages among the seven markets.

The error correction parameter estimated for the error correction term is sometimes called the speed of adjustment, and it indicates how quickly the economy moves back to the longrun equilibrium after a shock. In Table 8 , it can be seen that error correction term coefficients that are insignificant belong to HIS, KS11, and SSEC. This means that these indices are weakly exogenous to the system. The weak exogeneity of the indices further implies that the markets are the initial receptor of external shocks, and in turn transmit the shocks to the other markets in the observed region. As a result, the equilibrium relationship of the seven markets is disturbed. The adjustment back to equilibrium can be inferred from the signs and magnitude of the coefficients, $\mathrm{l}_{1}$, (DlHSI equation), $\mathrm{l}_{2}$ (DlKS11 equation), and $\mathrm{l}_{3}$, (DISSEC equation). The negative sign indicates that the respective index will pose a shock to the other indices in the observed region. In this sense, STI will give the largest negative impact on the other observed Asian markets since it has the greatest error term coefficient. N225, TWII, STI, and KLSE show error term coefficients that are even significant at one percent level.

Table 9 then shows that using daily price index during 2000-2003, HIS's error correction term is -0.129 but not significant while the rest of indices show significant error correction term coefficients. Compared to figures in Table 8 , the number of insignificant coefficients (at significance level of five percent) in Table 9 is fewer. In this period, STI is still the 
Gadjah Mada International Journal of Business, September - December 2008, Vol. 10, No. 3

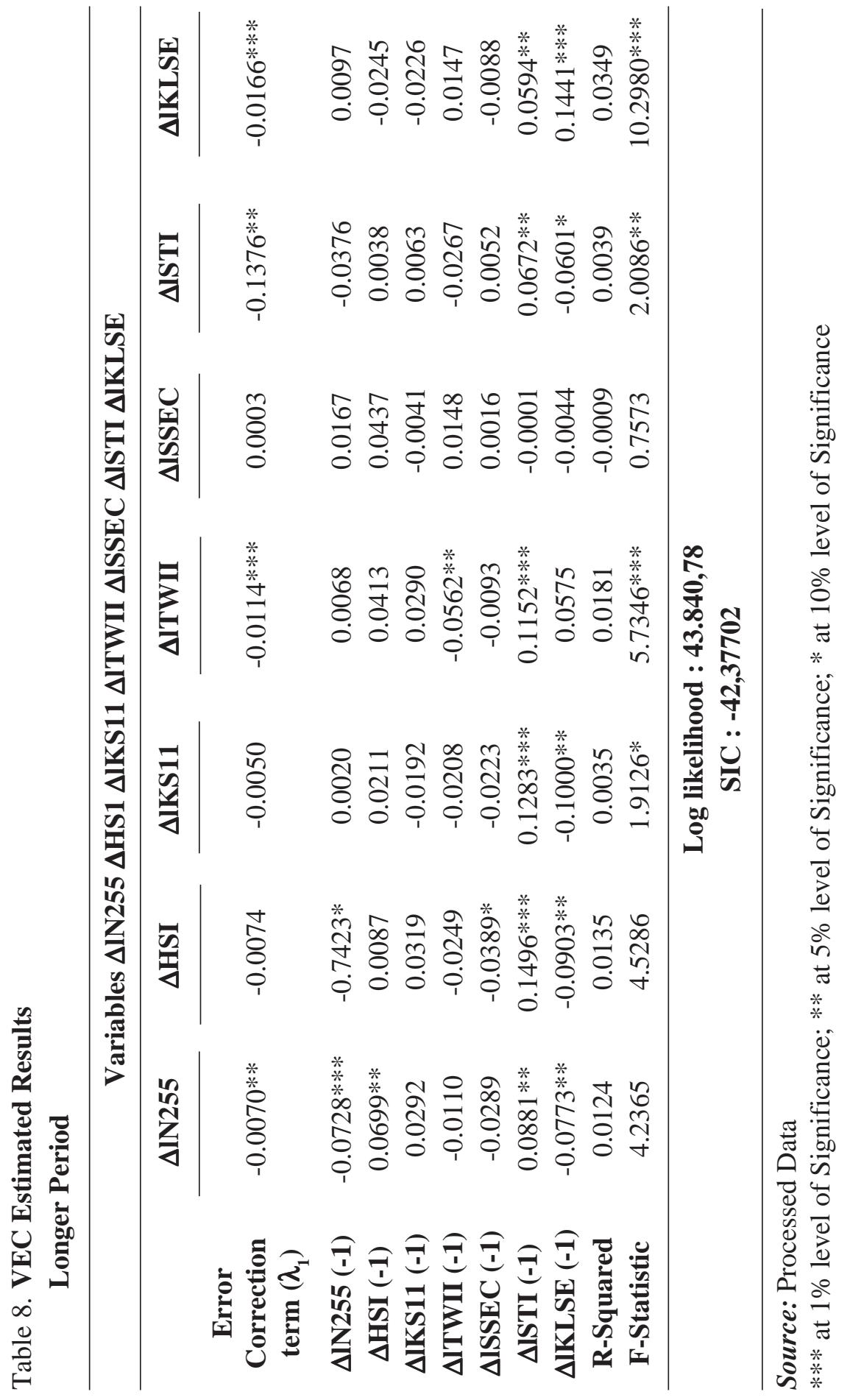


Herwany \& Febrian-Cointegration and Causality Analysis on Developed Asian

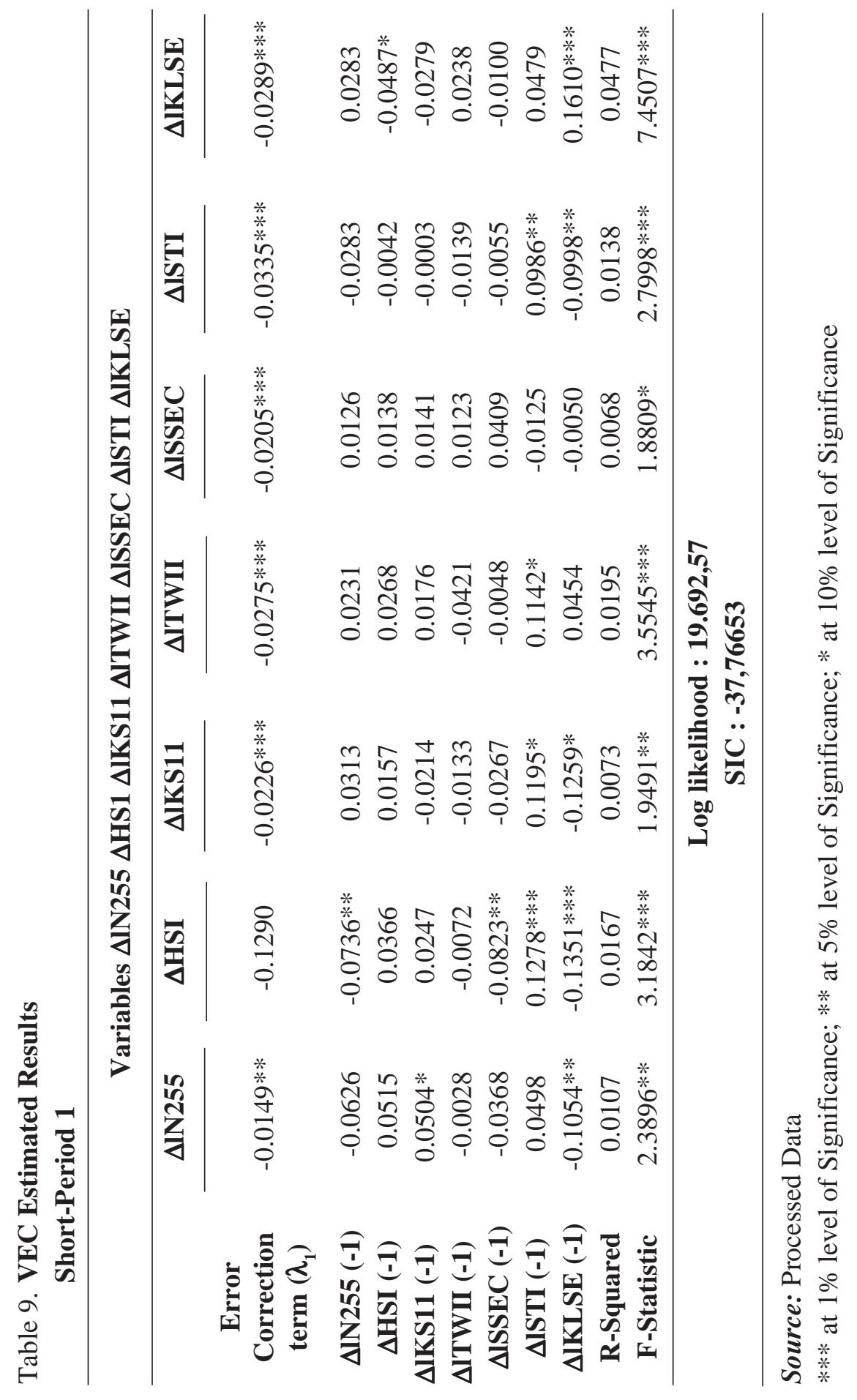


Gadjah Mada International Journal of Business, September - December 2008, Vol. 10, No. 3

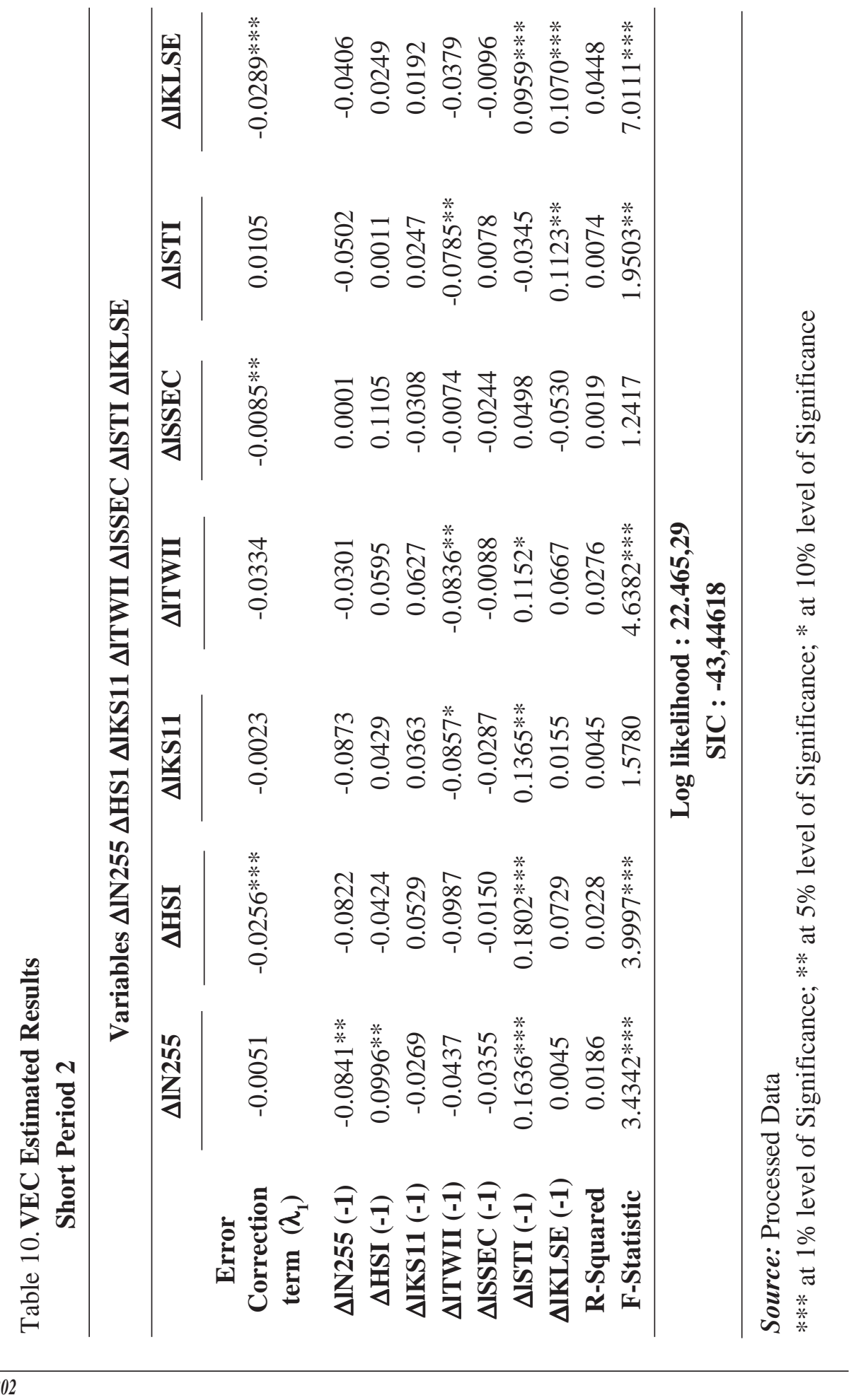


most significant shock-creator among the regional indices, recording a coefficient of -0.033 .

More drastic change can be seen in the results of the third test, presented in Table 10. In this period, N255, KS11, TWII, and STI show insignificant error correction term coefficients. KS11 records a decrease in the coefficient by 0.0027 , meaning that the index lowers its pressure to the system in the future. The error correction term coefficients on TWII, KS11, and STI show insignificant potential impacts on the regional market equilibrium. In this period, KLSE becomes the largest shock-creator in the observed region.

From the above vector error correction tests, we can observe that the decline in log likelihood values is consistent with the decrease in observation period. Meanwhile, the length of observation period does not affect the SIC value, which represents the suitability and fitness of a model. The SIC value resulting from the second shorter period test is larger than that from the longer period test. Overall, STI and $K L S E$ prove to be consistently significant index, as they produce significant coefficients in all assessment periods. Thus, these indices are proven cointegrated with other observed indices, and inclusion of the indices in a portfolio may prevent an investor from forming an optimum portfolio.

In Table 11, we can see that causal relationships exist among the observed markets. In the longer period data assessment, we may notice that HIS and
N225 show a two-way relationship. Such a relationship also applies to the pair of KLSE and STI. Similarly, a change in HSI affects the other observed indices, such as SSEC, STI, and KLSE. Therefore, we can infer that there are some stocks listed simultaneously on more than one market, and that the macroeconomic variables between two economies in the observed region are strongly correlated.

In the first shorter period, only the pair of HIS-KLSE shows two-way causal relationship. Meanwhile, a change in HSI leads to changes in N225, SSEC, STI, and KSLE. A change in KLSE may result from changes in N225, KS11, and STI. In the second shorter period, causal relationships exist in the pairs of STI-TWII and STIKLSE. N225 causes a change in HSI, whereas a change in TWII may result from changes in HSI, KS11, and STI.

It is worth noting that HSI consistently shows one-way causal relationship with STI in the three observation periods. The pair of STI-KLSE shows consistent causal relationship in all observation periods. This pair even exhibits two-way causal relationship in the second shorter period. We may conclude that these three indices have proven to have strong causal relationships beneficial for a portfolio diversification.

Meanwhile, the risk performance of each observed market is assessed using delta normal based Value at Risk. Using variance of each market displayed in Table 12, number of observations that vary across the observed 
Gadjah Mada International Journal of Business, September - December 2008, Vol. 10, No. 3

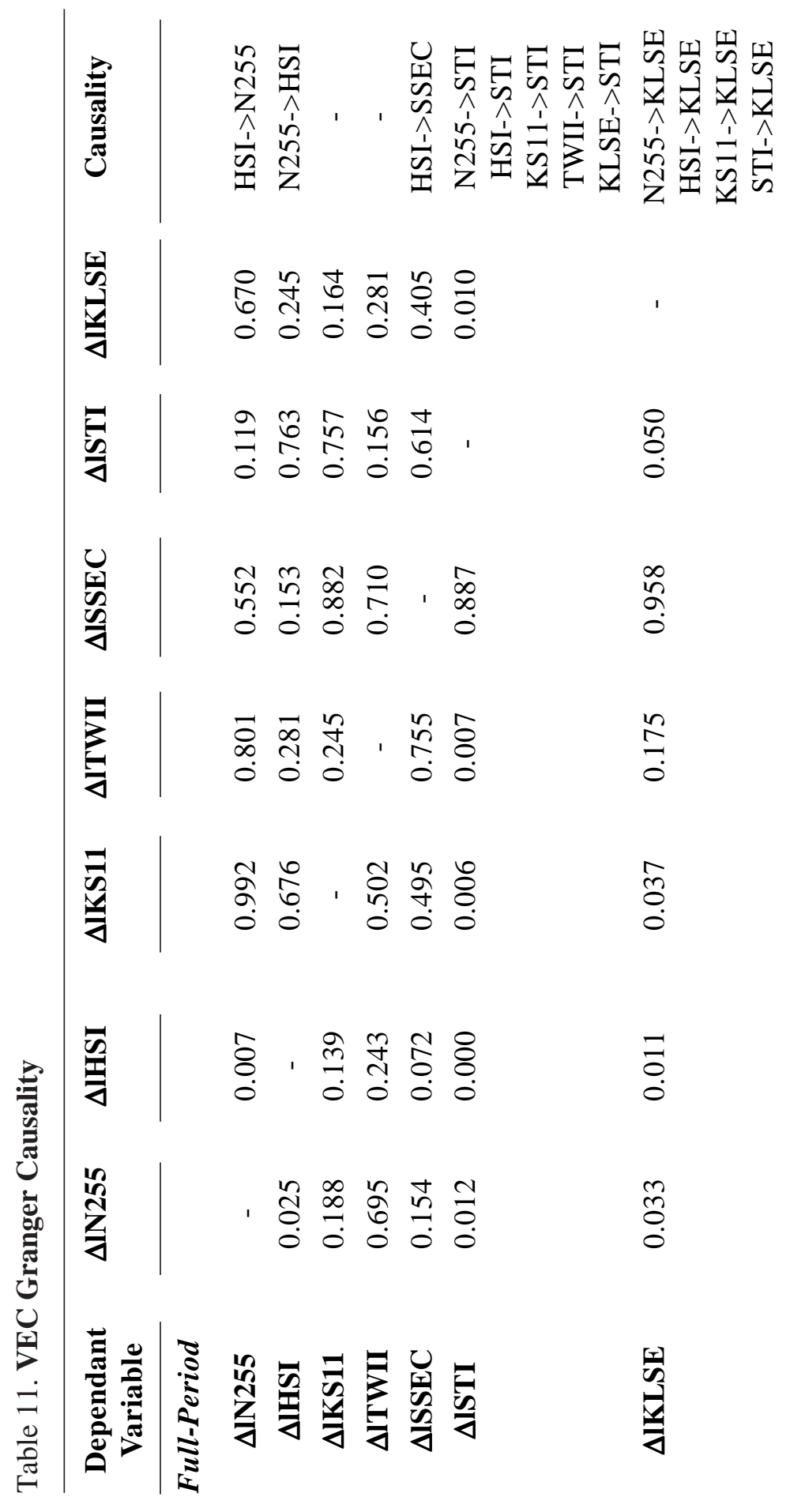


Herwany \& Febrian-Cointegration and Causality Analysis on Developed Asian

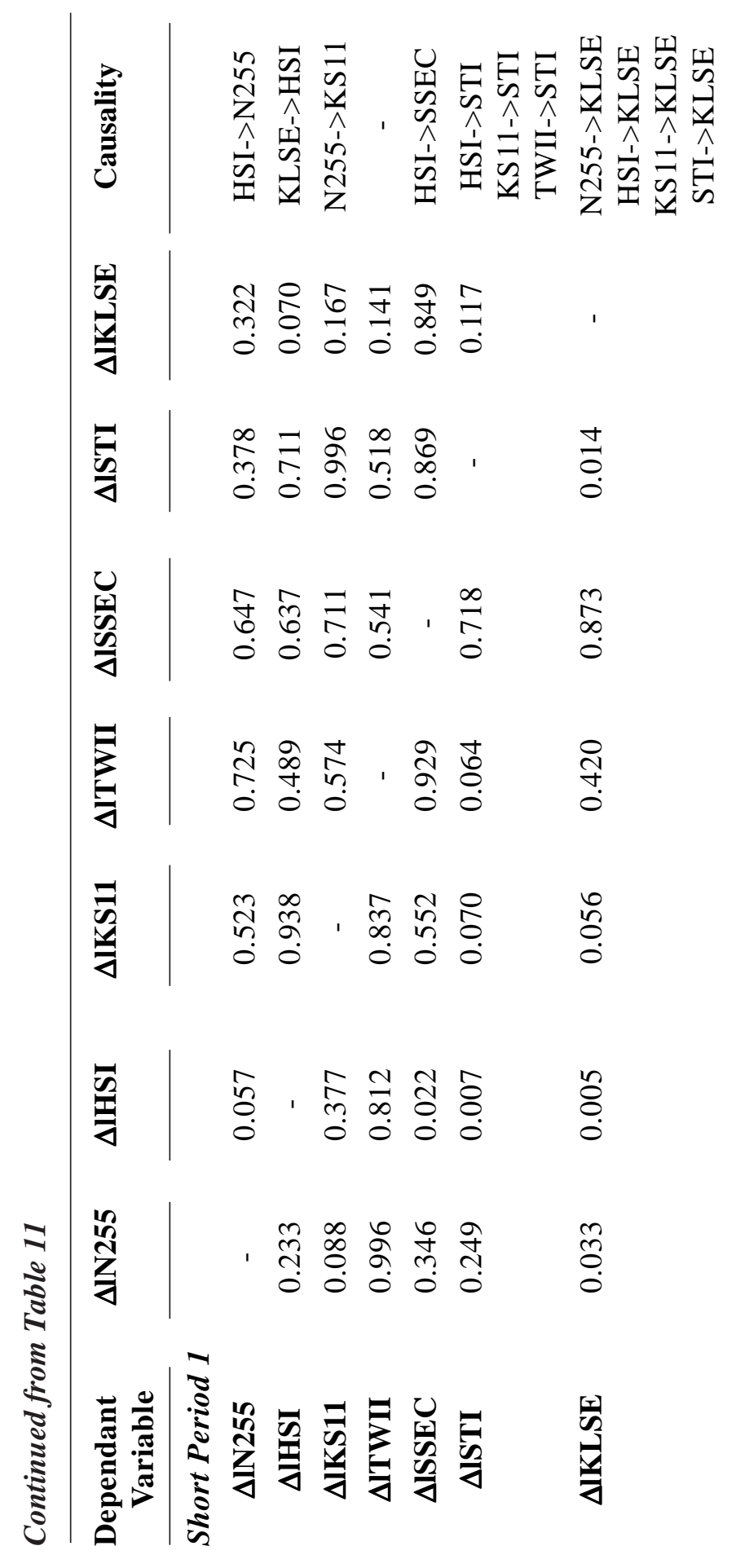


Gadjah Mada International Journal of Business, September - December 2008, Vol. 10, No. 3

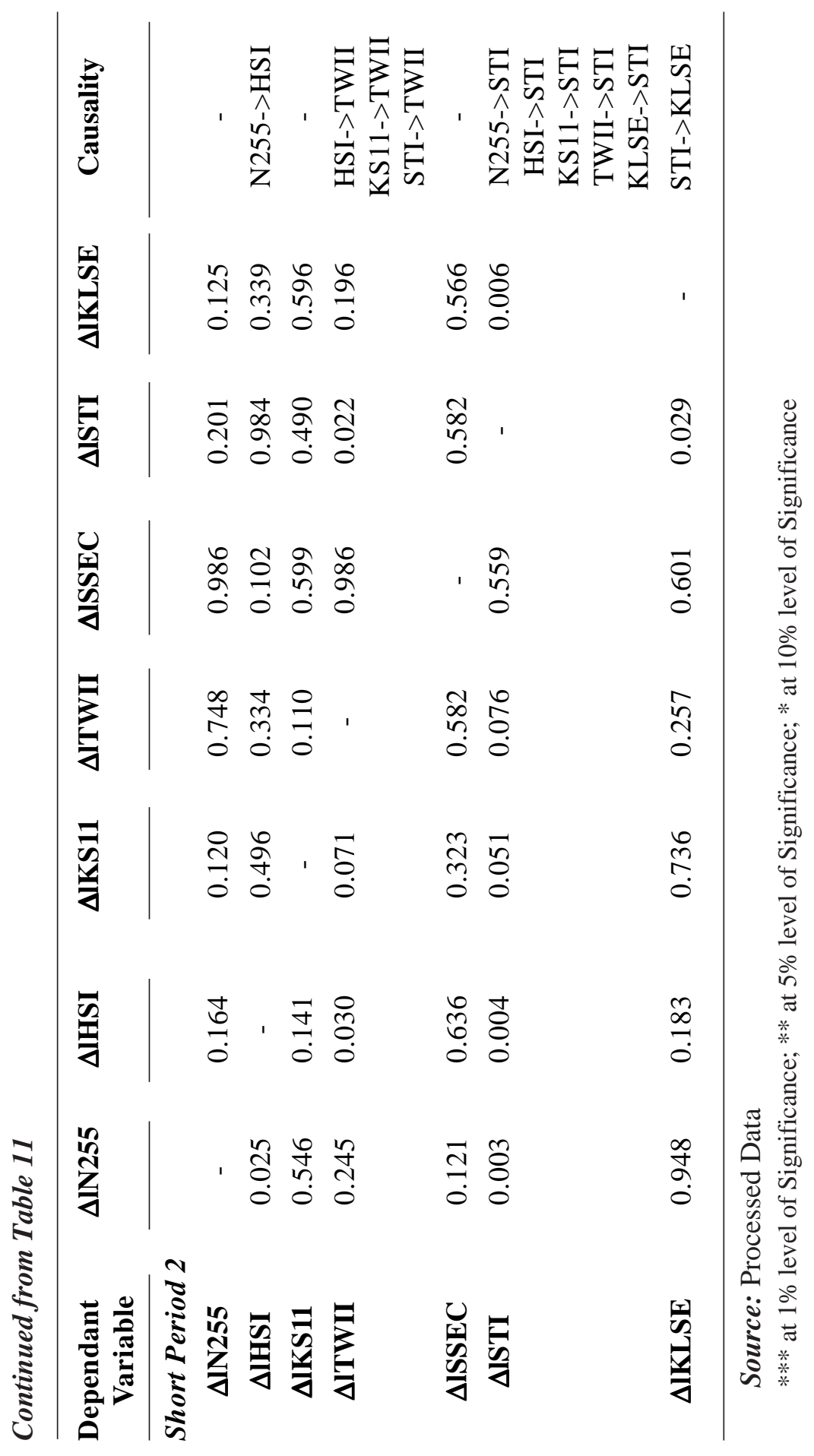


Herwany \& Febrian-Cointegration and Causality Analysis on Developed Asian

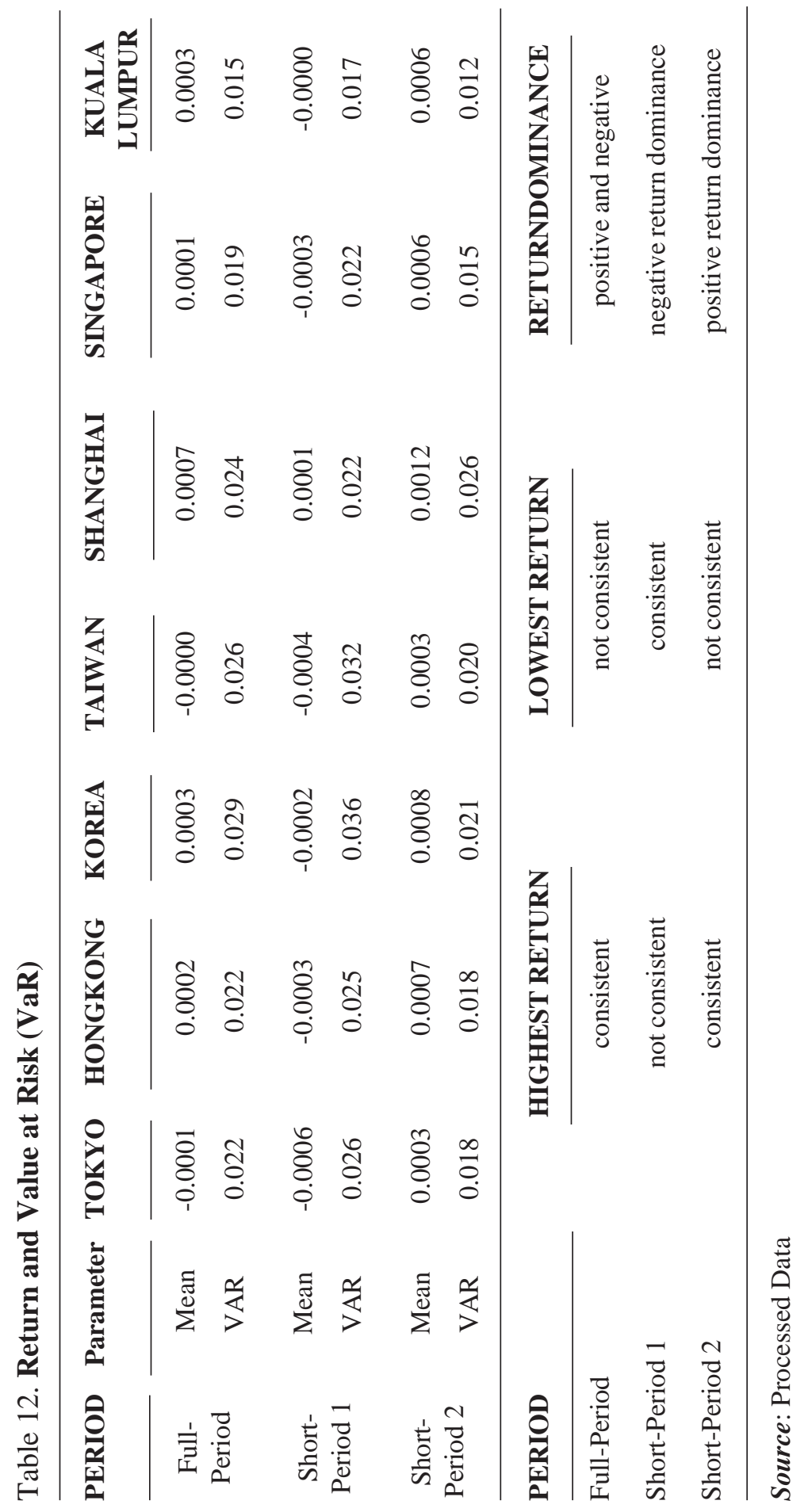


Gadjah Mada International Journal of Business, September - December 2008, Vol. 10, No. 3

markets, and significance level of 95 percent, our calculation ends up with the delta-normal-based Value at Risk as shown in Table 12. In the table, we can see that the highest risk or the greatest VaR belongs to KS11 (in longer and first shorter periods), and SSEC (in second shorter period). The results in longer observation and first shorter periods demonstrate a violation to the longtime acceptable convention in Finance, "high return for high risk", as SSEC exhibits the highest returns while KS11 bears the highest risks in these periods. The convention, however, holds in the second shorter period.

\section{Portfolio Strategy}

In an optimum portfolio formation process, there are many approaches that can be utilized, such as beta-based mean-variance analysis, $\mathrm{B} / \mathrm{M}$ value analysis, $\mathrm{P} / \mathrm{E}$ ratio analysis, portfolio diversification, etc. Findings of this study recommend several points for portfolio development:

Correlation coefficient approach. This approach may provide a positive output if the formation process employs return with the lowest correlation coefficient between stocks or indices. In this study, SSEC has the lowest correlation coefficients in all observation periods. Moreover, in the shorter period, almost all indices show increasing correlation coefficients. Therefore, this study recommends the use of longer period of observation for the portfolio selection process. It is worth noting that the correlation is related to return, not the price or the index, as it focuses more on the stationary process.

Cointegration approach. This approach focuses more on the potential new equilibrium resulting from longrun relationship magnitude. This study reveals that STI and KLSE are significantly cointegrated with other indices in the observed region.

VEC model approach. This method emphasizes the calculation of coefficient error term, which reflects potential future shocks resulting from an index or stock. This study empirically proves that HSI, KS11, and SSEC are shock-creator indices in the future equilibrium. This implies that one can build an optimum index portfolio by including only one of the three into a basket of the other four indices. The three indices cannot be put in one portfolio as they tend to move in the same direction. However, the relationships among the indices can be determined through the associated VEC value. HIS, TWII, STI, and KLSE have VEC values that are greater than one. KS11's VEC is less than one, while N225's VEC is equal to one. This evidence implies that KS11 moves faster than the rest observed indices.

Causality relationship approach. This method assesses the one-way and twoway causal relationships between markets or assets. This study shows that STImay experience the largest change resulting from changes in N255, HSI, KS11, TWII, and KLSE. In developing a portfolio, we may exclude STI as 
it also proves to be strongly correlated with other indices. The two-way causal relationship between STI and TWII, as well as between STI and KLSE, indicates that the inclusion of the three indices will not provide an optimum portfolio. The Granger's causality model is very helpful when one is to assess short-term portfolio.

Risk volatility approach. This method is focused on the assessment on return volatility of an index or asset. This study reveals that there is no consistent, linear relationship between risk and return. In the three observation periods, the high-return indices are not necessarily high-risk indices, and vice versa. Therefore, this study does not recommend the risk-return based portfolio selection.

\section{Summary and Conclusion}

This paper attempts to assess the relationships among the neighboring Asian indices by employing time series models. The results show plausible solutions to forming a portfolio by including Asian indices in the investment basket. This study reveals that approaches to establishing a portfolio will much be related to the selected assessment models. Mean-variance assessment model, for instance, is in fact very much related to the associated cointegration and ECM tests.

There are, however, some limitations that may prevent results of this study from generalization. This study cannot overcome the fact that different portfolio selection approach will give different portfolio outputs. Similarly, different assessment's length of observation period also will result in different outputs, as the duration may affect the correlation coefficient as well as the volatility.

In the light of risk management and portfolio selection, the formation of new equilibrium among markets can be of great consideration when one is to develop a portfolio. This is rendered by causal relationships among markets that may affect the expected diversification in a portfolio. A strong causal relationship, regardless of the direction, will accelerate formation of a new equilibrium between markets. Therefore, investors need to carefully examine the magnitude of inter-market relationships. The existence of a linear combination of the seven indices that forces these indices to have a long-term equilibrium relationship implies that the indices are perfectly correlated in the long run and diversification among these seven equity markets cannot benefit international portfolio investors. However, there can be excess returns in the short run. None of the aforementioned approaches provides similar recommendation. Thus, the portfolio selection will rely much on the investor's preference in choosing the associated assessment components. 
Gadjah Mada International Journal of Business, September - December 2008, Vol. 10, No. 3

\section{References}

Alexander, C. 1999. Optimal hedging using cointegration. Philosophical Transactions of the Royal Society A 357: 2039-2058.

Alexander, C. 2000. Cointegration-based trading strategies: A new approach to enhanced index tracking and statistical arbitrage. Manuscript, Banking.www.bankingmm.com: $1-6$.

Alexander, C. 2001. Market Models: A Guide to Financial Data Analysis. John Wiley and Sons: 347-388.

Alexander, C, and A. Dimitriu. 2003. Equity indexing, cointegration and stock price dispersion: A regime switching approach to market efficiency. ISMA Centre Discussion Papers in Finance 2003-02. U.K.: University of Reading.

Alexander, C, and Thillainathan. 1995. The Asian connection. Emerging Market Investor 2: $42-46$.

Chan, K., B. Gup, and M. Pan. 1992. An empirical analysis of stock prices in major Asian markets and the United Stated. The Financial Review 27: 289-307.

Chan, K., B. Gup, and M. Pan. 1997. International Stock Market Efficiency and Integration: A Study of Eighteen Nations. Journal of Business Finance and Accounting 24: 803-813.

Chandana, C., and B. Paratab. 2002. Foreign direct investment and growth in India: A cointegration approach. Applied Economics 34: 1061-1073.

Christensen, B. J., M. Ø. Nielsen. 2003. Asymptotic Normality of Narrow-Band Least Squares in the Stationary Fractional Cointegration Model and Volatility Forecasting. Denmark: University of Aarhus.

Corhay, A., A. Rad, and J. Urbain. 1993. Common stochastic trends in European Stock Markets. Economics Letters 42: 385-390.

DiBartolomeo, D. 1999. Active returns from passive management: Cointegration of country indices in EAFE. Northfield Information Services Manuscript. www.northinfo.com: l-8.c

Duan, J. C., and S. Pliska. 1998. Option valuation with cointegrated prices. Working Paper. Hong Kong: Department of Finance, Hong Kong University of Science and Technology.

Dwayer, G., and M. Wallace. 1992. Cointegration and market efficiency. Journal of International Money and Finance 11: 318-327.

Engle, R., and C. J. W. Granger. 1987. Cointegration and error-correction: Representation, estimation, and testing. Econometrica (March): 251-276.

Fraser, P., and O. Oyefeso. 2005. U.S., U.K., and European market integration. Journal of Business Finance and Accounting 32: 161-182.

French and Poterba. 1991. Investor diversification and international equity markets. American Economic Review (Papers and Proceedings) 81: 222-226.

Gerristis, R., and A. Yuce. 1999. Short- and long-term links among European and U.S. Stock Markets. Applied Financial Economics 9: 1-9. 
Herwany \& Febrian-Cointegration and Causality Analysis on Developed Asian

Granger, C. W. J., and R. Joyeux. 1980. An introduction to long memory time series models and fractional differencing. Journal of Time Series Analysis 1: 15-39.

Granger, C. W. J. 1981. Some properties of time series data and their use in econometric model specification. Journal of Econometrics 16: 121-130.

Granger, C. W. J., and J. J. Hallman. 1991. Long memory series with attractors. Oxford Bulletin of Economics and Statistics 53: 11-26.

Granger, C. W. J., and D. Morgenstern. 1970. Predictability of Stock Market Prices. Lexington, MA: Heath-Lexington Books.

Hall, S., and A. Milne. 1994. The relevance of p-star analysis to UK monetary policy. The Economic Journal 104: 597-604.

Hilliard, J. E. 1979. Relationship between equity indices on world exchanges. Journal of Finance 34: 103-114.

Jarque, C., and A. Bera. 1987. Test for normality of observations and regression residuals. International Statistical Review 55: 163-172.

Johansen, S. 1988. Statistical analysis of cointegrated vectors. Journal of Economic Dynamics and Control, 12,231-254.

Johansen, S., and K. Juselius. 1990. Maximum Likelihood Estimation and Inference on Cointegration with Application to the Demand for Money, Oxford Bulletin of Economics and Statistics, 52, 169-210.

Kasa, K. 1992. Common stochastic trends in international stock markets. Journal of Monetary Economics 29: 95-124.

Knif, J., and S. Pynnonen. 1999. Local and global price memory of international stock markets. Journal of International Financial Markets, Institutions and Money 9: 129147.

Kwan, A. C. C, A. H. B. Sim, and J. A. Cotsomitis. 1995. The causal relationships between equity indices on world exchanges. Applied Economics 27: 33-37.

Liu, X, P. Burridge, and P. Sinclair. 2002. Relationship between economic growth, foreign direct investment and trade: evidence from China. Applied Economics 34: 14331440.

Liu, X., and P. Romilly. 1997. An empirical investigation of the causal relationship between openness and economic growth in China. Applied economics 29: 1679- 86.

Lo, A., and C. MacKinlay. 1990. An econometric analysis of nonsynchronous trading. Journal of Econometrics 45: 181-211.

Lucas, A. 1997. Strategic and Tactical Asset Allocation and the Effect of Long-run Equilibrium Relations, Research Memorandum, 1997-42. Amsterdam: Vrije Universiteit.

MacKinnon, J. 1991. Critical values for cointegration tests. In Engle and C. W. J. Granger (eds.), Long-run Economic Relationships: Readings in Cointegration (chapter 13). Oxford University Press. 
Gadjah Mada International Journal of Business, September - December 2008, Vol. 10, No. 3

MacKinnon, J. 1996. Numerical distribution functions for unit root and cointegration tests. Journal of Applied Econometrics 11: 601-618.

MacKinnon, J., A. A. Haug, and L. Michelis. 1999. Numerical distribution functions of likelihood ratio tests for cointegration. Journal of Applied Econometrics 14: 563577.

Malliaris, A. G., and J. Urrita. 1992. The international crash of October 1987: Causality tests.

Journal of Financial and Quantitative Analysis 27 (3): 353-364.

Osterwald-Lenum, M. 1992. A note with quantiles of asymptotic distribution of the maximum likelihood cointegration rank test statistics. Oxford Bulletin of Economics and Statistics 54: 461-472.

Pan, M. S., Y. A. Liu, and H. J. Roth. 1999. Common stochastic trends and volatility in Asian Pacific equity markets. Global Finance Journal 10: 161-172.

Roca, E.. 1999. Short-term and long-term price linkages between the equity markets of Australia and its trading partners. Applied Financial Economics 9: 501-511.

Roca, E., E. Selvanathan, and W. Shepherd. 1998. Are the ASEAN equity markets interdependent? ASEAN Economic Bulletin 15: 109-121.

Smith, K. L., J. Brocato, and J. E. Rogers. 1993. Regularities in the data between major markets: Evidence from Granger causality tests. Applied Economics 3: 55-60.

Syriopoulos, T. 2003. Prospects for portfolio investments in emerging European Stock Markets. Paper presented on November 8th at the Second Annual Conference of the Hellenic Finance and Accounting Association. Greece: Athens.

Wang, X. 2005. Essays on risk management and dependence across stock markets. PhD Dissertation. NY: Albany State University. 